\title{
C-Reactive Protein, Chemerin, Fetuin-A and Osteopontin as Predictors of Cardiovascular Risks in Persons With Psoriasis Vulgaris
}

\author{
Pavel BORSKY ${ }^{1}$, Zdenek FIALA ${ }^{1}$, Ctirad ANDRYS $^{2}$, Martin BERANEK ${ }^{3}$, Kvetoslava \\ HAMAKOVA ${ }^{4}$, Jan KREMLACEK ${ }^{5}$, Andrea MALKOVA ${ }^{1}$, Tereza SVADLAKOVA ${ }^{1,2}$, Jan \\ KREJSEK $^{2}$, Vladimir PALICKA ${ }^{3}$, Vit REHACEK ${ }^{6}$, Lenka KOTINGOVA ${ }^{1}$, Lenka \\ BORSKA $^{1}$
}

${ }^{1}$ Institute of Preventive Medicine, Faculty of Medicine in Hradec Kralove, Charles University, Hradec Kralove, Czech Republic, ${ }^{2}$ Institute of Clinical Immunology and Allergology, University Hospital and Faculty of Medicine in Hradec Kralove, Charles University, Hradec Kralove, Czech Republic, ${ }^{3}$ Institute of Clinical Biochemistry and Diagnostics, University Hospital and Faculty of Medicine in Hradec Kralove, Charles University, Hradec Kralove, Czech Republic, ${ }^{4}$ Clinic of Dermal and Venereal Diseases, University Hospital, Hradec Kralove, Czech Republic, ${ }^{5}$ Institute of Pathological Physiology, Faculty of Medicine in Hradec Kralove, Charles University, Hradec Kralove, Czech Republic, ${ }^{6}$ Transfusion Center, University Hospital, Hradec Kralove, Czech Republic

Received February 9, 2021

Accepted February 25, 2021

Epub Ahead of Print May 12, 2021

\section{Summary}

The study aimed to contribute to understanding the role of CRP, chemerin, fetuin-A and osteopontin and to assess their suitability as biomarkers of early stages of cardiovascular diseases in psoriasis vulgaris. Serum levels measured in 28 patients and 22 controls. Patients: increased levels of CRP $(p<0.001)$, chemerin $(p<0.05)$, osteopontin $(p<0.05)$ and decreased levels of fetuin-A $(p<0.05)$, significant relationships between CRP and fetuin-A (rho=0.530, $p<0.01$ ), CRP and chemerin (rho $=0.543$, $\mathrm{p}<0.01), \mathrm{CRP}$ and age (rho $=0.590, \mathrm{p}<0.001)$, osteopontin and fetuin-A $(r=-0.415, p<0.05)$, chemerin and PASI score (rho=-0.424, $\mathrm{p}<0.05$ ). We confirmed specific roles of the biomarkers in psoriasis. CRP, fetuin-A and osteopontin could be considered appropriate markers for the detection of early stages of cardiovascular diseases.

\section{Key words}

Chemerin • CRP • Fetuin-A • Osteopontin • Psoriasis

\section{Corresponding author}

L. Borska, Institute of Preventive Medicine, Faculty of Medicine in Hradec Kralove, Charles University, Simkova 870, Hradec Kralove
500 03, Czech Republic. E-mail: borka@lfhk.cuni.cz

\section{Introduction}

Psoriasis vulgaris is an autoimmune disease that primarily affects the skin. It is characterized by keratinocyte hyperproliferation, angiogenesis and dysregulation of the normal immune response, which leads to chronic inflammation. It is not a mere skin disease. The pathogenesis of psoriasis is complex and results from a combination of genetic and epigenetic modifications and multifold environmental influences (Woo et al. 2017). It has been reported that the disease may be accompanied by an (increased risk for a multitude of systemic disorders - comorbidities). It is believed that $73 \%$ of patients suffering from psoriasis have at least one comorbidity (Machado-Pinto et al. 2016).

Psoriasis is associated with cardiovascular comorbidities and an increased prevalence of metabolic syndrome, diabetes and hyperlipidemia (Gelfand et al. 2006). The pathophysiology of this association is still to be fully discovered, but a systemic inflammatory reaction 
seems to be the common denominator for all of the abovementioned comorbidities (Woo et al. 2017). Systemic inflammation promotes vascular injury. During the process of vascular inflammation, pro-inflammatory cytokines, autoantibodies, cell adhesion molecules, oxidative damage and/or dyslipidemia initiate and promote vascular damage, which results in an increased risk of cardiovascular diseases (Cibickova et al. 2019, Nakao et al. 2019).

According to the literature, psoriasis is linked to vascular inflammation and to the presence of neutrophils (increased neutrophil count in peripheral blood) and systemic biomarkers of inflammation (Naik et al. 2015). As a result, increased morbidity and mortality can be observed (for the reasons of cardiovascular diseases, stroke, metabolic syndrome and chronic kidney diseases) (Strober et al. 2018).

Sometimes it is difficult to detect early stages of comorbidities, such as early stages of cardiovascular diseases. In this regard, it could be useful to determine risk by measuring some easily available proteins/glycoproteins whose expression is related to an increase in cardiovascular risk. For the purpose of our study, we chose 4 parameters: C-reactive protein (CRP), chemerin, fetuin-A and osteopontin. These parameters have never been published together in one study.

The activation of the inflammatory reaction, characterized by an increase in CRP, can play a role in the development of endothelial dysfunction, vascular injury and atherosclerosis, independent of standard risk factors (Vadakayil et al. 2015).

Chemerin is a novel adipokine that is highly produced in visceral adipose tissue and liver (Chiricozzi et al. 2018). This tissue protein is closely associated with chronic inflammation and adipogenesis. Chemerin promotes endothelial inflammation by promoting monocyte-endothelial cell adhesion, which is an essential step in the development of atherosclerosis (Inci et al. 2016). Recent data indicate that circulating chemerin is elevated in numerous metabolic and inflammatory diseases, including psoriasis, metabolic syndrome, obesity, diabetes mellitus, and cardiovascular diseases (Inci et al. 2016).

Fetuin-A is a multifunctional binding glycoprotein with transport function that is produced in the liver and then secreted into the systemic circulation (Simjak et al. 2018). It is an endogenous inhibitor of insulin receptor tyrosine kinase and is thus associated with insulin resistance, metabolic syndrome, and an increased risk for type 2 diabetes mellitus (Zhou et al. 2018). Increased levels of fetuin-A have been associated with an increased incidence of non-alcoholic fatty liver disease due to its pro-inflammatory effects. However, fetuin-A also has anti-inflammatory effects. Fetuin-A positively affects the acute phase in sepsis and endotoxemia and promotes wound healing (Mukhopadhyay et al. 2014). Fetuin-A also inhibits ectopic vascular mineralization and is thus considered to be responsible for as much as $50 \%$ of the calcification inhibitory capacity of human plasma (Pampanini et al. 2018). Its deficiency is associated with an increased incidence of ectopic vascular calcification in psoriatic patients (Genc et al. 2017) and an increased risk of cardiovascular mortality in patients suffering from coronary artery disease, independent of traditional risk factors (Chen et al. 2017).

Osteopontin is an extracellular structural phosphorylated glycoprotein that is secreted by many cell types. Its expression plays a role in many processes, including homeostatic regulation, acute and chronic inflammation fibrosis, cell survival and particularly in the biomineralization of tissues and in bone remodeling (Filardi et al. 2019). High levels of serum or plasma osteopontin have been reported in various inflammatory and autoimmune diseases, such as cardiovascular events, rheumatoid arthritis, lupus erythematosus, multiple sclerosis and psoriasis (Vena et al. 2010, Li et al. 2018). Schreier et al. also found that serum osteopontin is positively related to soluble VCAM-1, which is involved in the progression of endothelial dysfunction and atherosclerosis (Schreier et al. 2016).

The present study contributes to understanding the role of CRP, chemerin, fetuin-A and osteopontin in the pathogenesis of psoriasis and assesses the suitability of these markers for the detection of early stages of cardiovascular diseases in persons with psoriasis.

\section{Methods}

\section{Observed and control group}

The observed group consisted of 28 patients (15 men and 13 women) with acute psoriasis vulgaris. The median age of the patients was 50 years (upper and lower quartiles 35.5 and 55.8). They were hospitalized at the Department of Dermatology and Venereology, University Hospital Hradec Kralove, the Czech Republic. For at least two weeks before the blood sampling, the patients were not treated by any drugs influencing inflammatory reactions or systemic drugs. The patients 
who suffered from psoriatic arthritis, acute infections, or other inflammatory diseases were not admitted to the study (Table 1).

The control group consisted of 22 healthy blood donors (11 men and 11 women). The median age of the controls was 50 years (upper and lower quartiles 49 and 51.8). For at least two weeks before blood sampling, the controls were not treated by any drugs influencing inflammatory reactions or systemic drugs (Table 1).

The study was approved by the Ethics Committee of the University Hospital in Hradec Kralove, the Czech Republic (project identification code: PROGRES Q40-09, Q40-10 and Q40-11; reference number: 201705 183P; date of approval: May 2, 2017). Informed written consent was obtained from all persons.

Table 1. Observed and Control group.

\begin{tabular}{lccc}
\hline Variable & Patients $(\mathbf{n}=\mathbf{2 8})$ & Controls $(\mathbf{n}=\mathbf{2 2})$ & p-value \\
\hline Age & $50.0(35.5-55.8)$ & $50.0(49.0-51.8)$ & NS \\
BMI $\left(\mathrm{kg} / \mathrm{m}^{2}\right)$ & $28.1(25.4-29.1)$ & $27.2(25.1-30.0)$ & $\mathrm{NS}$ \\
CRP $(\mathrm{mg} / \mathrm{liter})$ & $3.1(2.1-5.5)$ & $1.4(1.1-1.7)$ & $<0.001$ \\
Chemerin $(\mathrm{pg} / \mathrm{ml})$ & $11799.0(9255.8-14037.8)$ & $8592.0(5045.8-12569.3)$ & $<0.05$ \\
Fetuin-A $(\mu \mathrm{g} / \mathrm{ml})$ & $266.6(233.5-314.7)$ & $309.8(281.1-336.5)$ & $<0.05$ \\
Osteopontin $(\mathrm{pg} / \mathrm{ml})$ & $4773.5(2731.5-9256.5)$ & $3025.0(1900.0-4680.5)$ & $<0.05$ \\
\hline
\end{tabular}

The data are presented as medians and upper and lower quartiles (in brackets).

\section{Body mass index and PASI score}

The intensity/severity of psoriasis was calculated from basic characteristics of disease status (desquamation, erythema and skin infiltration) and expressed as the PASI (Psoriasis Area and Severity Index) score (Malkic et al. 2015). In both groups (patients and controls), body mass index (BMI) was calculated as the ratio of weight to height squared $\left(\mathrm{kg} / \mathrm{m}^{2}\right)$.

\section{$C R P$, chemerin, fetuin- $A$ and osteopontin}

In both groups, peripheral blood samples from the cubital vein were collected using Vacutainer sampling tubes (Becton Dickinson). Blood serum was then isolated, and serum samples were frozen $\left(-70^{\circ} \mathrm{C}\right)$ until analysis. Repeated thawing and freezing cycles were avoided.

The serum level of CRP was determined by immuno-nephelometry (IMMAGE 800, Beckman, Brea, CA, USA). The results were expressed as milligrams per liter of serum with a detection limit of $1.0 \mathrm{mg}$ per liter.

The serum level of human fetuin-A was determined by sandwich enzyme-linked immunosorbent assay (human fetuin-A ELISA commercial kit, BioVendor Research and Diagnostic Products, the Czech Republic). The test was performed according to the manufacturer's instructions, and serum samples were diluted before analysis at 1:10 000. Absorbance values were determined at $450 \mathrm{~nm} / 620 \mathrm{~nm}$ by the Multiskan RC ELISA Reader (Thermo Fisher Scientific, USA). The results were expressed as micrograms per milliliter of serum with a detection limit of $20 \mu \mathrm{g}$ per milliliter.

The serum levels of osteopontin and chemerin were detected simultaneously by multiplexed microspherebased XMAP Luminex technology (Luminex Magnetic Screening Assay kit, manufactured by R\&D Systems, USA). The test was performed according to the manufacturer's instructions, and serum samples were diluted 1:2 before analysis for both proteins. Microbeads were read with the Bio-Plex 200 Reader, and the results were expressed as picograms per milliliter of serum with a detection limit of $378 \mathrm{pg} / \mathrm{ml}$ for osteopontin and 79 for chemerin.

\section{Statistical analysis}

Based on the Anderson-Darling test for data distribution, the parametric or nonparametric test was used to ensure test sensitivity (for the differences between the psoriatic patients and control group). The data were statistically processed with R software version 3.3.2 using the "nortest" and "ggplot2" packages. Associations between all clinical and/or laboratory parameters were evaluated either by Pearson's or by Spearman's rank order correlation tests; intergroup differences were assessed using Student's $t$-test or the Wilcoxon rank-sum test. Our differences were considered statistically significant when the probability level (p) was below the alpha level of 0.05 . 


\section{Results}

The group of patients was not significantly different from the group of controls in terms of BMI and age. The median PASI score in patients was 18.7 (upper and lower quartiles 14.6 and 20.9). In the group of patients, we found significantly higher levels of CRP $(p<0.001)$, chemerin $(p<0.05)$, and osteopontin $(p<0.05)$, whereas the level of fetuin-A was significantly lower $(p<0.05)$ (Table 1). There were significant relationships between the levels of CRP and fetuin-A (Spearman's rho $=0.530, \mathrm{p}<0.01$, Fig. 1B) and between the levels of CRP and chemerin (Spearman's rho $=0.543, \mathrm{p}<0.01$,
Fig. 1C) in patients. The previously mentioned relationships were not significant in the control group and, in addition, unlike patients, showed a negative trend (Fig. 1F, 1G). The patients also exhibited a significant negative relationship between the levels of osteopontin and fetuin-A (Pearson's $\mathrm{r}=-0.415, \mathrm{p}<0.05$, Fig. 1A). This relationship was not significant in the control group (Fig. 1E). Finally, in the group of patients, we found a significant negative relationship between chemerin and PASI score (Spearman's rho=-0.424, p $<0.05$, Fig. 1D) and a significant relationship between the level of CRP and age (Spearman's rho=0.590, $\mathrm{p}<0.001$ ).

c)
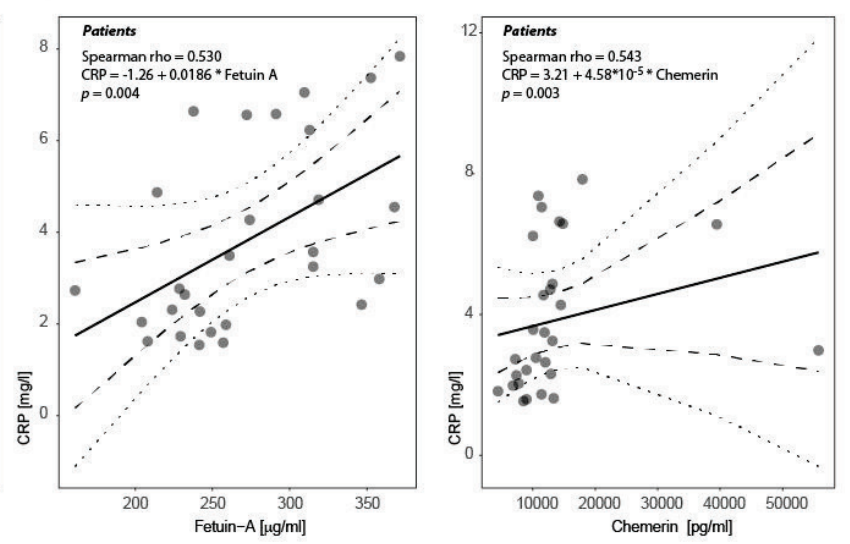

d)

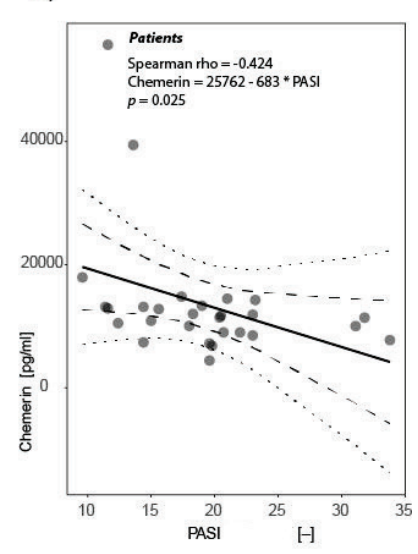

g)
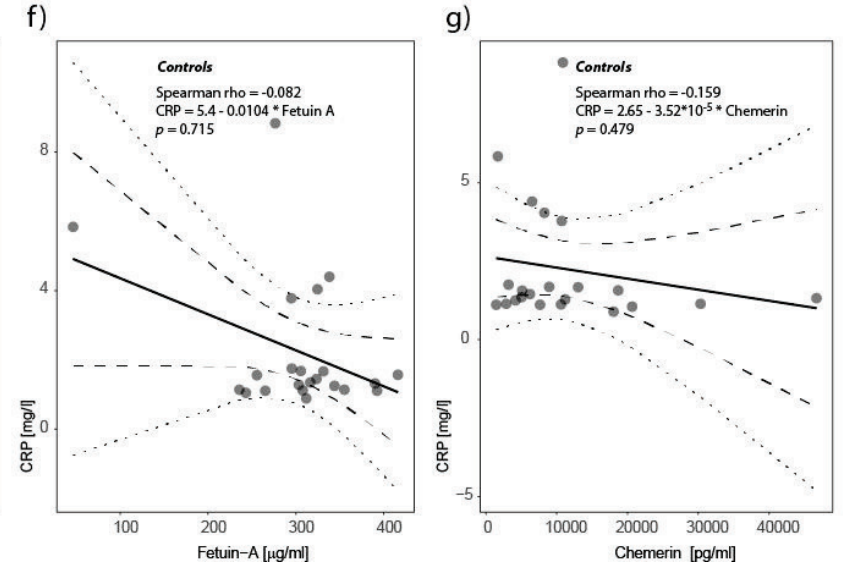

b)
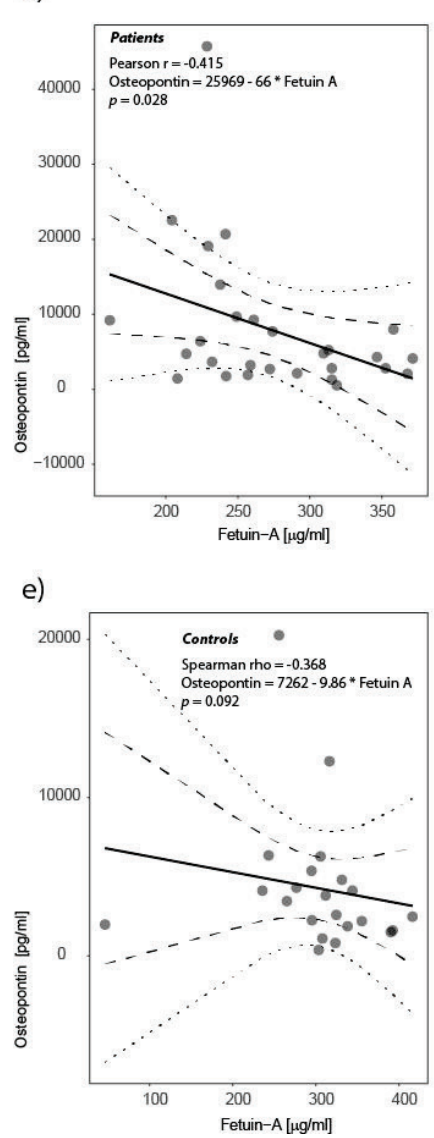

Fig. 1. Relationship between studied parameters. The black solid line represents a linear regression with confidence intervals of the estimate depicted by dotted $(99.9 \%$ ) and dashed (95\%) curves. (a) Significant negative relationship between osteopontin and fetuin-A in patients. (b) Significant relationship between CRP and fetuin-A in patients. (c) Significant relationship between CRP and chemerin in patients. (d) Significant relationship between chemerin and PASI in patients. (e) Insignificant negative relationship between osteopontin and fetuin-A in controls. (f) Insignificant negative relationship between CRP and fetuin-A in controls. (g) Insignificant negative relationship between CRP and chemerin in controls.

\section{Discussion}

Age-related diseases such as cardiovascular diseases are now crucial problems worldwide. Systemic inflammation plays a significant role in the different aspects of cardiovascular disease pathogenesis, including the development of endothelial dysfunction and atherosclerosis in persons with psoriasis (Snekvik et al. 2018).

Various molecules modulate the functions of 
cardiovascular and immune organs. CRP is one of the basic indicators of systemic inflammation, and an elevated level of CRP indicates acute phases of inflammation in different autoimmune diseases (Ctirad et al. 2008, Dong et al. 2017, Kassem et al. 2019). It was confirmed that even slightly increased CRP can indicate an increased level of future cardiovascular risk in healthy subjects (Evrin et al. 2005). In our study, we found significantly higher serum levels of CRP in psoriatic patients than in controls $(\mathrm{p}<0.001)$, which indicates both the presence of systemic inflammation and elevated cardiovascular risk and suggests that endothelial dysfunction is present.

Age can significantly modify the degree of systemic inflammation (Beranek et al. 2017). In accordance with this fact, we found a significant relationship between the level of CRP and age in the group of patients (Spearman's rho $=0.590, \mathrm{p}<0.001$ ). In view of this finding, the CRP level could be considered an appropriate age-dependent indicator of the early stages of cardiovascular comorbidities in psoriatic patients.

In persons with psoriasis, some studies described significant relationships between CRP and PASI score (Sudhesan et al. 2016) and between CRP and BMI (Coban et al. 2016); however, other studies have not confirmed these findings (Gisondi et al. 2013, Baran et al. 2015). The results of our study also did not confirm the significance of the abovementioned relationships (CRP with PASI, Spearman's rho $=-0.291, \mathrm{p}=0.132$ and CRP with BMI, Spearman's rho=0.288, $\mathrm{p}=0.137$ ).

In summary, the available data suggest that CRP is significantly involved in the pathophysiology of psoriasis and seems appropriate for the detection of the early stages of cardiovascular diseases in persons with psoriasis.

The chemoattractive protein chemerin is a multifaceted adipokine that stimulates the chemotaxis of dendritic cells and macrophages to the site of inflammation. It was reported that chemerin plays a crucial role in the process of vascular injury through vascular smooth muscle cell oxidative stress and inflammation in a ChemR23-inhibitable manner (Mariani and Roncucci 2015). Chemerin plays a role in activating pro-inflammatory $\mathrm{NF}-\kappa \mathrm{B}$ in human endothelial cells, enhances the secretion of endothelial cell adhesion molecules (E-selectin, VCAM-1, and ICAM-1) and promotes monocyte-endothelial cell adhesion (Dimitriadis et al. 2018).

It was found that chemerin levels correlate with other important markers of metabolic and cardiovascular diseases, including BMI, triacylglycerols and blood pressure (Zabel et al. 2005).

Increased levels of chemerin have also been detected in lesional psoriatic skin compared to normal skin (Chiricozzi et al. 2018). Coban et al. also found a significant relationship between PASI score and chemerin (Coban et al. 2016). However, some other studies have not confirmed this relationship (Gisondi et al. 2013). Consistent with the abovementioned studies, we found significantly increased chemerin levels in persons with psoriasis $(\mathrm{p}<0.05$, compared to the controls); nevertheless, unlike the two abovementioned studies, the nature of the relationship between chemerin and PASI score was negative in our group of patients (Fig. 1D).

Aksu et al. found that chemerin was significantly associated with the components of metabolic syndrome, such as body mass index (BMI), in psoriatic patients (Aksu et al. 2017). However, we did not confirm this phenomenon in our study (Spearman's rho=0.340, $\mathrm{p}=0.076$ ).

Gisondi et al. reported higher levels of CRP and chemerin in persons with psoriasis (compared to the controls) and a significant relationship between chemerin and CRP in patients (Gisondi et al. 2013). In our study, we found a significant relationship between chemerin and CRP in patients (Fig. 1C) but not in the control group (as seen from the picture, the relationship trend in the control group was negative, Fig. 1G).

As mentioned above, chemerin can be associated with inflammation and psoriasis, but there are only limited studies demonstrating an association between serum levels of chemerin and the development of cardiovascular diseases, especially atherosclerosis (Ferland and Watts 2015, Inci et al. 2016). According to our current knowledge, only one study has been conducted so far, in which it was confirmed that chemerin could be used as a marker to screen for psoriatic patients with subclinical cardiac involvement (Aksu et al. 2017).

The available data suggest that chemerin has both an anti-inflammatory and a pro-inflammatory effect; however, it is still not clear whether anti-inflammatory or pro-inflammatory activity is prevalent. This phenomenon can be attributed to dissimilar roles played by chemerin via various isomers (chemerin can be secreted in an inactive form and activated after cleavage) in different phases (at the initiation, maintenance or answer) of 
inflammation. It is obvious that chemerin exhibits various effects depending on the way that is induced (Inci et al. 2016).

Overall, chemerin plays a very complex and still not entirely clear role in the pathophysiology of psoriasis. The available data do not allow us to conclude the suitability of chemerin as a marker of the early stages of the cardiovascular comorbidities of psoriasis.

The available data indicate that the role of fetuin-A in organisms is very complex and includes both pro-inflammatory and anti-inflammatory processes. In the group of persons with psoriasis, we found a significantly decreased level of fetuin-A $(\mathrm{p}<0.05)$ in comparison to controls. This result is in accordance with the findings of Gerdes et al. (2014), which suggested that the decreased levels of fetuin-A may be related to the presence of an acute phase of inflammation. Fetuin-A is currently known as a negative acute phase protein (Baran et al. 2015). By contrast, we found a significant (positive) relationship between fetuin-A and CRP (a basic indicator of systemic inflammation, Spearman's $\mathrm{rho}=0.530$, $\mathrm{p}<0.01$, Fig. 1B). It is interesting that this relationship was not significant in the control group, where the data even showed a negative trend (Fig. 1F).

The serum level of fetuin-A was found to be inversely correlated with mitral annular calcification (Ziyrek et al. 2013). Vascular calcification is an active process characterized by the ectopic deposition of minerals in the vasculatures and immune cell infiltration in the vasculatures (Ge et al. 2017, Vassalle and Mazzone 2016). Vascular damage is recognized as a chronic disease and a predictor of future cardiac events, significantly increasing the risk of cardiovascular morbidity/mortality and significantly contributing to coronary atherosclerosis progression. Likewise, vascular damage is an important late marker of atherosclerosis (Ge et al. 2017, Vassalle and Mazzone 2016, Yeh and Willerson 2003).

Psoriatic patients are determined to have a high degree of vascular calcification. Genc et al. described that a low level of fetuin-A may have a role in psoriasis pathogenesis and may contribute to the vascular calcification process developed in psoriasis. More precisely, lower fetuin-A levels are associated with an increased incidence of ectopic vascular calcification in psoriatic patients and an increased risk of cardiovascular disease (Genc et al. 2017).

In accordance with the abovementioned study results, we also found a significantly lower level of
fetuin-A $(\mathrm{p}<0.05)$ in the persons with psoriasis. Recent literature has described that inflammatory reactions are key factors in both ectopic vascular calcification and cardiovascular risk (Avogaro and Fadini 2015). It might be possible that psoriasis-related inflammation contributes to a reduction in systemic fetuin-A levels that, by contrast, increases the risk of vascular calcification and cardiovascular diseases.

In summary, fetuin-A plays a very complex and still not entirely clear role in the pathophysiology of psoriasis. The available data suggest that fetuin-A seems appropriate for the detection of the early stages of the cardiovascular comorbidities of psoriasis.

Osteopontin is involved in the pathophysiology of psoriasis by different mechanisms through its expression by lesional keratinocytes, inflammatory cells, and endothelial cells (Li et al. 2018, Abdel-Mawla et al. 2016).

Clinical studies describe findings of increased serum levels of osteopontin in patients with atherosclerosis and myocardial infarction (Filardi et al. 2019, Uz et al. 2009). In addition, osteopontin plays a significant role in atherosclerotic vasculopathy by inducing inflammation and by inhibiting ectopic vascular calcification (Steitz et al. 2002). These findings seem to support the role of osteopontin as an emerging biomarker of cardiovascular risk (Filardi et al. 2019). Schreier et al. also confirmed that osteopontin is a suitable marker of early endothelial dysfunction (Schreier et al. 2016).

Consistent with the abovementioned studies, we found significantly higher serum levels of osteopontin $(p<0.05)$ in the persons with psoriasis than in the controls. An interesting finding was a significant negative relationship between osteopontin and fetuin- $\mathrm{A}$ in the group of persons with psoriasis (Fig. 1A, Pearson $r=-0.415, p<0.05)$. The trend of the relationship between osteopontin and fetuin-A was also negative in the control group but did not reach statistical significance (Fig. 1E, Spearman $\mathrm{r}=-0.368, \mathrm{p}=0.092$ ).

A limitation of the study is the relatively low number of patients in the study. This fact is determined by the strict exclusion criteria and low number of patients requiring doctor visits in the population.

We confirmed that CRP, chemerin, fetuin-A and osteopontin play specific roles in the pathophysiology of psoriasis. Chemerin exhibited a significant relationship with the severity of the disease. CRP, fetuin-A and osteopontin could be considered appropriate markers of endothelial dysfunction for the detection of the early 
stages of cardiovascular diseases in persons with psoriasis.

\section{Conflict of Interest}

There is no conflict of interest.

\section{Acknowledgements}

The study was supported by Charles University, Faculty of Medicine in Hradec Kralove, the Czech Republic by projects Q40-09, Q40-10, Q40-11 and SVV-260543/2020. The authors acknowledge Mgr. Dana Knajflova for text proofreading and linguistics.

\section{References}

ABDEL-MAWLA MY, EL-KASHESHY KA, GHONEMY S, AL BALAT W, ELSAYED AA: Role of osteopontin in psoriasis: An immunohistochemical study. Indian J Dermatol 61: 301-307, 2016. https://doi.org/10.4103/0019$\underline{5154.182434}$

AKSU F, CALISKAN M, KELES N, EREK TOPRAK A, UZUCAKMAK TK, KOSTEK O, YILMAZ Y, DEMIRCIOGLU K, CEKIN E, OZTURK I, KARADAG AS: Chemerin as a marker of subclinical cardiac involvement in psoriatic patients. Cardiol J 24: 276-283, 2017. https://doi.org/10.5603/CJ.a2017.0031

AVOGARO A, FADINI GP: Mechanisms of ectopic calcification: Implications for diabetic vasculopathy. Cardiovasc Diagn Ther 5: 343-352, 2015. https://doi.org/10.3978/j.issn.2223-3652.2015.06.05

BARAN A, FLISIAK I, JAROSZEWICZ J, SWIDERSKA M: Effect of psoriasis activity on serum adiponectin and leptin levels. Postepy Dermatol Alergol 32: 101-106, 2015. https://doi.org/10.5114/pdia.2014.40960

BERANEK M, FIALA Z, KREMLACEK J, ANDRYS C, KREJSEK J, HAMAKOVA K, CHMELAROVA M, PALICKA V, BORSKA L: Changes in circulating cell-free DNA and nucleosomes in patients with exacerbated psoriasis. Arch Dermatol Res 309: 815-821, 2017. https://doi.org/10.1007/s00403-017-1785-5

CHEN X, ZHANG Y, CHEN Q, LI Q, LI Y, LING W: Lower plasma fetuin-a levels are associated with a higher mortality risk in patients with coronary artery disease. Arterioscler Thromb Vasc Biol 37: 2213-2219, 2017. https://doi.org/10.1161/ATVBAHA.117.309700

CHIRICOZZI A, ROMANELLI P, VOLPE E, BORSELLINO G, ROMANELLI M: Scanning the immunopathogenesis of psoriasis. Int J Mol Sci 19: 179, 2018. https://doi.org/10.3390/ijms19010179

CIBICKOVA L, LANGOVA K, VAVERKOVA H, LUKES J, CIBICEK N, KARASEK D: Superior role of waist circumference to body-mass index in the prediction of cardiometabolic risk in dyslipidemic patients. Physiol Res 68: 931-938, 2019. https://doi.org/10.33549/physiolres.934176

COBAN M, TASLI L, TURGUT S, OOZKAN S, TUNC ATA M, AKIN F: Association of adipokines, insulin resistance, hypertension and dyslipidemia in patients with psoriasis vulgaris. Ann Dermatol 28: 74-79, 2016. https://doi.org/10.5021/ad.2016.28.1.74

CTIRAD A, LENKA B, DAVID P, ZDENEK F, KVETA H, KAREL E, JAN K: Goeckerman's therapy for psoriasis with special reference to serum pentraxin 3 level. Int $J$ Dermatol 47: 1011-1014, 2008. https://doi.org/10.1111/j.1365-4632.2008.03666.x

DIMITRIADIS GK, KAUR J, ADYA R, MIRAS AD, MATTU HS, HATTERSLEY JG, KALTSAS G, TAN BK, RANDEVA HS: Chemerin induces endothelial cell inflammation: Activation of nuclear factor-kappa beta and monocyte-endothelial adhesion. Oncotarget 9: 16678-16690, 2018. https://doi.org/10.18632/oncotarget.24659

DONG X, YAN X, ZHANG W, TANG S: Adiponectin enhances biological functions of vascular endothelial progenitor cells through the mTOR-STAT3 signaling pathway. Physiol Res 67: 563-570, 2018. https://doi.org/10.33549/physiolres.933738

EVRIN PE, NILSSON SE, OBERG T, MALMBERG B: Serum C-reactive protein in elderly men and women: Association with mortality, morbidity and various biochemical values. Scand J Clin Lab Invest 65: 23-31, 2005. https://doi.org/10.1080/00365510510013505

FERLAND DJ, WATTS SW: Chemerin: A comprehensive review elucidating the need for cardiovascular research. Pharmacol Res 99: 351-361, 2015. https://doi.org/10.1016/j.phrs.2015.07.018 
FILARDI T, CARNEVALE V, MASSOUD R, RUSSO C, NIEDDU L, TAVAGLIONE F, TURINESE I, LENZI A, ROMAGNOLI E, MORANO S: High serum osteopontin levels are associated with prevalent fractures and worse lipid profile in post-menopausal women with type 2 diabetes. J Endocrinol Invest 42: 295-301, 2019. https://doi.org/10.1007/s40618-018-0914-0

GE Q, RUAN CC, MA Y, TANG XF, WU QH, WANG JG, ZHU DL, GAO PJ: Osteopontin regulates macrophage activation and osteoclast formation in hypertensive patients with vascular calcification. Sci Rep 7: 40253, 2017. https://doi.org/10.1038/srep40253

GELFAND JM, NEIMANN AL, SHIN DB, WANG X, MARGOLIS DJ, TROXEL AB: Risk of myocardial infarction in patients with psoriasis. JAMA 296: 1735-1741, 2006. https://doi.org/10.1001/jama.296.14.1735

GENC M, CAN M, GUVEN B, CINAR S, BUYUKUYUSAL C, ACIKGOZ B, MUNGAN AG, ACIKGOZ S: Evaluation of serum fetuin-a and osteoprotegerin levels in patients with psoriasis. Indian J Clin Biochem 32: 90-94, 2017. https://doi.org/10.1007/s12291-016-0570-0

GERDES S, OSADTSCHY S, BUHLES N, BAURECHT H, MROWIETZ U: Cardiovascular biomarkers in patients with psoriasis. Exp Dermatol 23: 322-325. https://doi.org/10.1111/exd.12381

GISONDI P, LORA V, BONAUGURI C, RUSSO A, LIPPI G, GIROLOMONI G: Serum chemerin is increased in patients with chronic plaque psoriasis and normalizes following treatment with infliximab. Br J Dermatol 168: 749-755, 2013. https://doi.org/10.1111/bjd.12118

INCI S, AKSAN G, DOGAN P: Chemerin as an independent predictor of cardiovascular risk. Ther Adv Endocrinol Metab 7: 57-68, 2016. https://doi.org/10.1177/2042018816629894

KASSEM MM, HELKIN A, MAIER KG, GAHTAN V: Thrombospondins differentially regulate proteins involved in arterial remodeling. Physiol Res 68: 893-900, 2019. https://doi.org/10.33549/physiolres.934148

LI J, CAI Y, WANG Z, DENG A, YANG G: Polymorphisms in the osteopontin are associated with susceptibility to ankylosing spondylitis in a Han Chinese population. Biomed Res Int 5: 1-6, 2018. https://doi.org/10.1155/2018/3458439

MACHADO-PINTO J, DINIZ MDOS S, BAVOSO NC: Psoriasis: New comorbidities. An Bras Dermatol 91: 8-14, 2016. https://doi.org/10.1590/abd1806-4841.20164169

MALKIC SALIHBEGOVIC E, HADZIGRAHIC N, CICKUSIC AJ: Psoriasis and metabolic syndrome. Med Arch 69: 85-87, 2015. https://doi.org/10.5455/medarh.2015.69.85-87

MARIANI F, RONCUCCI L: Chemerin/chemr23 axis in inflammation onset and resolution. Inflamm Res 64: 85-95, 2015. https://doi.org/10.1007/s00011-014-0792-7

MUKHOPADHYAY S, MONDAL SA, KUMAR M, DUTTA D: Proinflammatory and antiinflammatory attributes of fetuin-a: A novel hepatokine modulating cardiovascular and glycemic outcomes in metabolic syndrome. Endocr Pract 20: 1345-1351, 2014. https://doi.org/10.4158/EP14421.RA

NAIK HB, NATARAJAN B, STANSKY E, AHLMAN MA, TEAGUE H, SALAHUDDIN T, NG Q, JOSHI A, KRISHNAMOORTHY P, DAVE J, ROSE SM, DOVEIKIS J, PLAYFORD MP, PRUSSICK RB, EHRLICH A, KAPLAN MJ, LOCKSHIN BN, GELFAND JM, MEHTA NN: Severity of psoriasis associates with aortic vascular inflammation detected by FDG PET/CT and neutrophil activation in a prospective observational study. Arterioscler Thromb Vasc Biol 35: 2667-2676, 2015. https://doi.org/10.1161/ATVBAHA.115.306460

NAKAO M, NAKAMURA K, FUKASAWA T, SHIDA R, ITO A, ICHIMURA Y, TAKAHASHI T, MITSUI A, YOSHIZAKI A, SHIBATA S, KAMATA M, ARAKI M, WATANABE R, SATO S, ASANO Y: Assessment of endothelial function during the loading phase of infliximab in psoriasis: A potential predictor of its drug survival. Int J Dermatol 58: 54-59, 2019. https://doi.org/10.1111/ijd.14200

PAMPANINI V, INZAGHI E, GERMANI D, ALTERIO A, PUGLIANIELlO A, ALISI A, NOBILI V, CIANFARANI S: Serum fetuin-a levels in obese children with biopsy proven nonalcoholic fatty liver disease. Nutr Metab Cardiovasc Dis 28: 71-76, 2018. https://doi.org/10.1016/j.numecd.2017.09.008

SCHREIER M, SCHWARTZE JT, LANDGRAF K, SCHEUERMANN K, ERBS S, HERBERTH G, POSPISILIK JA, KRATZSCH J, KIESS W, KORNER A: Osteopontin is bmi-independently related to early endothelial dysfunction in children. J Clin Endocrinol Metab 101: 4161-4169, 2016. https://doi.org/10.1210/jc.2016-2238 
SIMJAK P, CINKAJZLOVA A, ANDERLOVA K, KLOUCKOVA J, KRATOCHVILOVA H, LACINOVA Z, KAVALKOVA P, KREJCI H, MRAZ M, PARIZEK A, KRSEK M, HALUZIK M: Changes in plasma concentrations and mRNA expression of hepatokines fetuin A, fetuin B and FGF21 in physiological pregnancy and gestational diabetes mellitus. Physiol Res 67 (Suppl 3): S531-S542, 2018. https://doi.org/10.33549/physiolres.934017

SNEKVIK I, NILSEN TIL, ROMUNDSTAD PR, SAUNES M: Psoriasis and cardiovascular disease risk factors: The HUNT study, Norway. J Eur Acad Dermatol Venereol 32: 776-782, 2018. https://doi.org/10.1111/jdv.14835

STEITZ SA, SPEER MY, MCKEE MD, LIAW L, ALMEIDA M, YANG H, GIACHELLI CM: Osteopontin inhibits mineral deposition and promotes regression of ectopic calcification. Am J Pathol 161: 2035-2046, 2002. https://doi.org/10.1016/S0002-9440(10)64482-3

STROBER B, KARKI C, MASON M, GUO N, HOLMGREN SH, GREENBERG JD: Characterization of disease burden, comorbidities, and treatment use in a large, us-based cohort: Results from the corrona psoriasis registry. J Am Acad Dermatol 78: 323-332, 2018. https://doi.org/10.1016/i.jaad.2017.10.012

SUDHESAN A, RAJAPPA M, CHANDRASHEKAR L, ANANTHANARAYANAN PH, THAPPA DM, SATHEESH S, CHANDASEKARAN A, DEVARAJU P: Association of c-reactive protein (rs1205) gene polymorphism with susceptibility to psoriasis in south Indian Tamils. J Clin Diagn Res 10: GC01-GC04, 2016. https://doi.org/10.7860/JCDR/2016/23391.8624

UZ O, KARDESOGLU E, YIGINER O, BAS S, IPCIOGLU OM, OZMEN N, APARCI M, CINGOZBAY BY, ISILAK Z, CEBECI BS: The relationship between coronary calcification and the metabolic markers of osteopontin, fetuin-a, and visfatin. Turk Kardiyol Dern Ars 37: 397-402, 2009.

VADAKAYIL AR, DANDEKERI S, KAMBIL SM, ALI NM: Role of c-reactive protein as a marker of disease severity and cardiovascular risk in patients with psoriasis. Indian Dermatol Online J 6: 322-325, 2015. https://doi.org/10.4103/2229-5178.164483

VASSALLE C, MAZZONE A: Bone loss and vascular calcification: A bi-directional interplay? Vascul Pharmacol 86: 77-86, 2016. https://doi.org/10.1016/j.vph.2016.07.003

VENA GA, VESTITA M, CASSANO N: Psoriasis and cardiovascular disease. Dermatol Ther 23: 144-151, 2010. https://doi.org/10.1111/j.1529-8019.2010.01308.x

WOO YR, CHO DH, PARK HJ: Molecular mechanisms and management of a cutaneous inflammatory disorder: Psoriasis. Int J Mol Sci 18: 2684, 2017. https://doi.org/10.3390/ijms18122684

YEH ET, WILLERSON JT: Coming of age of c-reactive protein: Using inflammation markers in cardiology. Circulation 107: 370-371, 2003. https://doi.org/10.1161/01.CIR.0000053731.05365.5A

ZABEL BA, ALLEN SJ, KULIG P, ALLEN JA, CICHY J, HANDEL TM, BUTCER EC: Chemerin activation by serine proteases of the coagulation, fibrinolytic, and inflammatory cascades. J Biol Chem 280: 34661-34666, 2005. https://doi.org/10.1074/jbc.M504868200

ZHOU ZW, JU HX, SUN MZ, CHEN HM, FU QP, JIANG DM: Serum fetuin-a levels in obese and non-obese subjects with and without type 2 diabetes mellitus. Clin Chim Acta 476: 98-102, 2018. https://doi.org/10.1016/j.cca.2017.11.023

ZIYREK M, TAYYARECI Y, YURDAKUL S, SAHIN ST, YILDIRIMTURK O, AYTEKIN S: Association of mitral annular calcification with endothelial dysfunction, carotid intima-media thickness and serum fetuin-A: An observational study. Anadolu Kardiyol Derg 13: 752-758, 2013. https://doi.org/10.5152/akd.2013.235 